\title{
Polymer endgroup control through a trifunctional cobalt- mediated radical polymerization: new avenues for synthesising protein conjugates
}

Meri Ayurini†, Peter G. Chandler†, David Rudd, Karen D. Milewska, Lara Malins, Ashley M. Buckle*, Joel F. Hooper*

\begin{abstract}
Cobalt-mediated radical polymerisations (CMRPs) have been initiated by the radical decarboxylation of tetrachlorophthalimide activated esters. This allows for the controlled radical polymerisation of both activated and less activated monomers across a broad temperature range with a single cobalt species, with incorporation of polymer endgroups derived from simple carboxylic acids derivatives and termination with an organozinc reagent. This method has been applied to the synthesis of a water-soluble protein/polymer conjugate, demonstrating the first example of CMRP in protein conjugation.
\end{abstract}

Cobalt-mediated radical polymerisation (CMRP) is a powerful method for the synthesis of polymers with controlled molecular weight and dispersity. The CMRP method relies on the labile nature of the $\mathrm{Co}$ (III)-carbon bond under thermal and photochemical conditions, allowing for polymerisation of unsaturated monomers to occur by reversible deactivation or degenerative chain transfer mechanisms, depending on the monomer and Co complex used. ${ }^{1}$

Due to the facile homolytic cleavage of the Co-C bond, ${ }^{2}$ rates of CMRPs can approach that of uncontrolled free radical polymerisations. ${ }^{1 a}$ This makes CMRP particularly well suited to the polymerisation of less activated monomers (LAMS) ${ }^{3}$ such as vinyl esters ${ }^{4}$ and amides, ${ }^{5}$ ethylene ${ }^{6}$ and 1 -octene, ${ }^{7}$ and perfluoroalkylethylenes. ${ }^{8}$

The high reactivity and lower temperatures associated with many CMRP applications has limited the range of suitable radical initiators that can be used (Scheme 1). The controlled polymerisation of vinyl acetate (VA) was first demonstrated using $\mathrm{Co}(\mathrm{acac})_{2}$ and the diazo initiator $\mathrm{V} 70$ at $30{ }^{\circ} \mathrm{C} .{ }^{4 a}$ This method generates the reactive organocobalt(III) species in situ, although the requirement to store and transport $\mathrm{V} 70$ at $-20{ }^{\circ} \mathrm{C}$ limits its broad application

\section{$\left[{ }^{\star}\right]$ M. Ayurini, J. F. Hooper}

Department of Chemistry, Monash University

Clayton 3800, Victoria, Australia

E-mail: joel.hooper@monash.edu

[*] P. G. Chandler, A. M. Buckle,

Department of Biochemistry and Molecular Biology,

Biomedicine Discovery Institute, Monash University

Clayton 3800, Victoria, Australia

Email: ashley.buckle@monash.edu

K. D. Milewska, L. Malins

Research School of Chemistry, Australian National University

Acton, 2601, ACT, Australia

D. Rudd

Monash Institute of Pharmaceutical Science,

Parkville, 3052, Victoria, Australia

M. Ayurini

Chemistry Department, Universitas Pertamina, South Jakarta, 12220,

Indonesia

[†] These authors contributed equally to this work

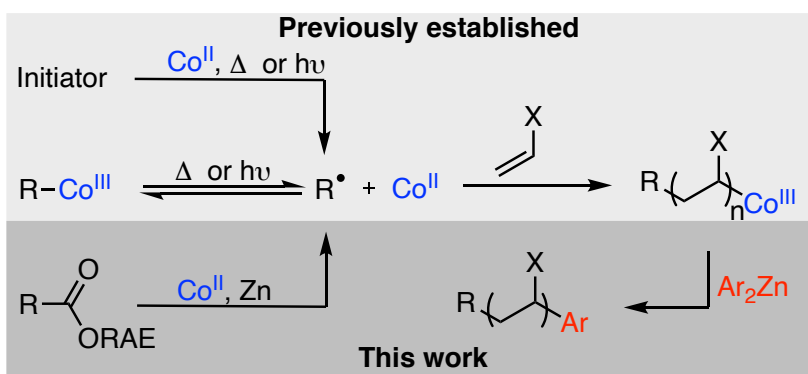

Scheme 1 - Initiation of cobalt mediated radical polymerisations

Low temperature initiation has also been achieved using photoinitiators, allowing for the controlled polymerisation of acrylate monomers at $0{ }^{\circ} \mathrm{C}$ under visible light irradiation. ${ }^{9}$

Along with control of the molecular weight and dispersity of a polymer, the ability to control the polymer endgroups is essential for many applications. In CMRP, the $\alpha$-endgroup is derived from the initiating radical, or from the cleavage of the initial Co-C bond in the case of organocobalt(III) complexes. This has been exploited to introduce functional endgroups through the synthesis of halomethyl-cobalt complexes, allowing for further elaboration of the polymer by azide substitution and copper catalysed alkyne cycloaddition reaction. ${ }^{10}$

Due to the versatile reactivity of organocobalt(III) complexes, a number of methods have been developed for $\omega$-endgroup functionalisation in CMRP. Radical trapping reagents such as nitroxides ${ }^{11}$ and thiols have been used extensively to functionalise polymers and remove cobalt from the resulting materials. Addition to $\mathrm{C}^{12} \mathrm{1}^{12}$ and carbon nanotubes ${ }^{13}$ has also been demonstrated, along with polymer-polymer coupling via addition to dienes. ${ }^{14}$ Polymer endgroup control is essential for the development of biological medicines based on polymer/protein conjugates. These hybrid materials can impart longer half-lives in the bloodstream compared with unfuctionalised proteins, although all FDA approved conjugates to date have utilised poly(ethylene glycol) (PEG). ${ }^{15}$ The exploration of alternatives to simple PEGylation of protein therapeutics will provide advancements in the design of polymers which improve pharmacokinetics (PK) or the rational design of novel functional materials. ${ }^{16}$

Recently, the decarboxylation of carboxylic acids and esters has emerged as a practical method for producing alkyl radicals in small-molecule cross-coupling chemistry. ${ }^{17}$ In 2016, Baran demonstrated that single-electron transfer from a Ni' intermediate could trigger the radical decarboxylation of $\mathrm{N}$-hydroxyphthalimide (NHP) esters, ${ }^{18}$ resulting in formation of an alkyl-Nill complex which could undergo coupling with an organozinc reagent. ${ }^{19}$ This method has subsequently been extended to the coupling of redox active esters (RAEs) with a variety of partners, including aryl and 
vinyl haides, ${ }^{20}$ aryl boronates ${ }^{21}$ and alkynes. ${ }^{22}$ In 2018, Wang and coworkers showed that cobalt is also an effective catalyst for the coupling of NHP esters with organozinc reagents, proceeding via the single electron transfer from a Col intermediate. ${ }^{23}$

Based on this precedent, we hypothesised that the in situ generation of a Co' species would allow for single electron transfer and radical decarboxylation of a redox active ester, producing both the initiating radical derived from the ester functional group and the required $\mathrm{Co}^{\prime \prime}$ complex to mediate radical polymerisation. We selected Cbz-phenylalanine as an appropriate starting material for the synthesis of redox-active esters 1-3, containing azabenzotriazole, phthalimide and tetrachlorophthalimide ${ }^{24}$ activating groups respectively.

Table 1 - Optimisation of polymerisation conditions with redox active esters.

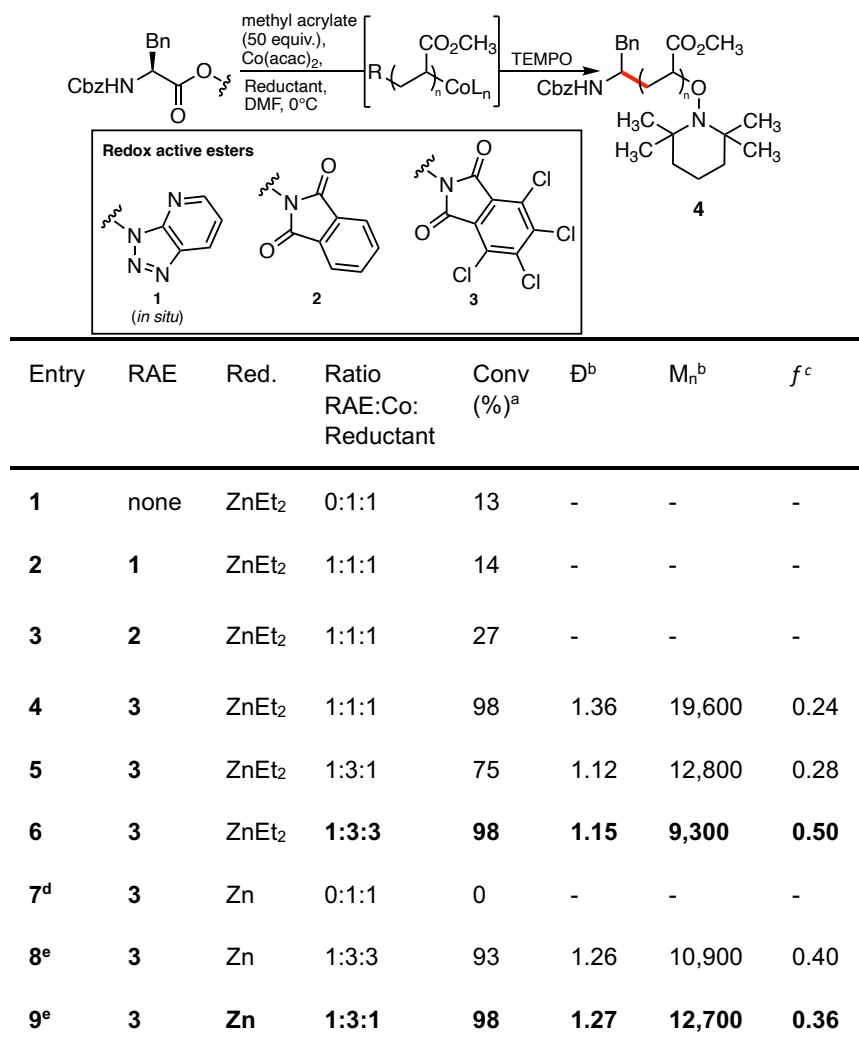

a Determined by ${ }^{1} \mathrm{H}$ NMR spectroscopy, ${ }^{\mathrm{b}}$ Determined by GPC, ${ }^{\mathrm{c}} f=\mathrm{M}_{\mathrm{n} \text {, theory }} / \mathrm{M}_{\mathrm{n}, \mathrm{obs}}{ }^{\mathrm{d}}$ Run at room temperature overnight ${ }^{e}$ Run at $0^{\circ} \mathrm{C}$ for $2 \mathrm{~h}$ then $3-4^{\circ} \mathrm{C}$ for $2 \mathrm{~h}{ }^{\mathrm{f}} 250$ equivalents of monomer used

We began our polymerisation experiments employing equimolar amounts of the redox-active ester (RAE) and $\mathrm{Co}(\mathrm{acac})_{2}$, with 50 equivalents of methyl acrylate in DMF. One equivalent of $\mathrm{ZnEt}_{2}$ was then added, to reduce the $\mathrm{Co}^{\prime \prime}$ to $\mathrm{Co}^{\prime}$ and initiate the radical decarboxylation. When ester 1 was generated in situ by reaction of the carboxylic acid with HATU, only $14 \%$ monomer conversion was seen after 18 hours. This was almost identical to the control experiment containing no activated ester, suggesting that 1 was not undergoing the desired radical decarboxylation (Table 1, Entries 1 and 2). While the use of isolated ester 2 resulted in a slightly increased conversion of $27 \%$, we were pleased to see that ester 3 gave $98 \%$ monomer conversion after $3 \mathrm{~h}$ at $0{ }^{\circ} \mathrm{C}$ (Entries 3 and 4 ). Following the polymerisation step, the resulting polymer was functionalised by the addition of TEMPO and isolated by precipitation.

Analysis of this polymer (Entry 4) by gel permeation chromatography $(\mathrm{GPC})$ showed a low dispersity $(\Xi=1.36)$ and a molecular weight of 19,600 . This observed molecular weight $\left(\mathrm{M}_{\mathrm{n}, \mathrm{obs}}\right)$ is almost four times higher than the calculated theoretical molecular weight $\left(M_{n, \text { theory }}\right)$ giving an initiation efficiency $(f)$ of 0.24 (where $f=M_{n, \text { theory }} / M_{n, o b s)}{ }^{25}$ This indicates that only $24 \%$ of the radicals that can be theoretically generated by the radical decarboxylation of $\mathbf{3}$ are resulting in polymer formation. To address this issue, we increased the amount of $\mathrm{Co}(\mathrm{acac})_{2}$ to 3 equivalents (Entry 5), which reduced the monomer conversion to $75 \%$ and the dispersity to 1.12 . However, the initiation efficiency remained almost constant at 0.28 . We next increased the amount of $\mathrm{ZnEt}_{2}$ to 3 equivalents, maintaining a 1:1 ratio between $\mathrm{Co}$ and Zn (Entry 6). This resulted in excellent monomer conversion and dispersity of 1.15 , along with a reduced $M_{n}$ of 9300 , resulting in an initiation efficiency of 0.50 .

The ${ }^{1} \mathrm{H}$ NMR spectra of this polymer showed the aromatic signals associated with the ester-derived endgroup, although integration suggests that only approximately $58 \%$ of the polymer chains have incorporated the desired endgroup, possibly due to the presence of other initiating radicals not derived from the activated ester.

Further examination of the ${ }^{1} \mathrm{HNMR}$ spectra showed a small triplet at $\delta 0.85 \mathrm{ppm}$, consistent with the incorporation of an ethyl group derived from $\mathrm{ZnEt}_{2}$. The presence of this signal, along with the $13 \%$ monomer conversion observed in the absence of redox active ester (Table 1, Entry 1) led us to suggest that this background polymerisation is initiated by an ethyl radical, possibly generated by the reaction of $\mathrm{ZnEt}_{2}$ with trace oxygen. ${ }^{26}$

Analysis of polymer 4 (entry 6 ) by MALDI/TOF mass spectroscopy showed two major species, the first consistent with incorporation of the phenylalanine derived endgroup and fragmentation of the TEMPO group and the $\mathrm{Cbz}$ imide ${ }^{27}$ (6251.56 calcd. for $\mathrm{n}=70$, found 6251.58, $\left.[\mathrm{M}+\mathrm{Ag}]^{+}\right)$and the second consistent with incorporation of the ethyl endgroup and loss of TEMPO (6178.53 calcd. for $\mathrm{n}=70$, found $6178.50,\left[\mathrm{M}+\mathrm{H}_{2} \mathrm{O}+\mathrm{Ag}\right]^{+}$).

In an effort to avoid this competing initiation mechanism, we substituted the $\mathrm{ZnEt}_{2}$ reducing agent for $\mathrm{Zn}$ powder. In the absence of the ester $\mathbf{3}$, this produced no detectable polymerization (entry 7). When a 1:3:3 ration of 3:RAE:Co was used (Entry 8), excellent conversion and molecular weight were observed, while a 1:3:1 ration (Entry 9 ) gave similar results, but with slightly improved incorporation of the TEMPO endgroup. As such, the conditions in Entry 9 were adopted as our standard conditions for further study.

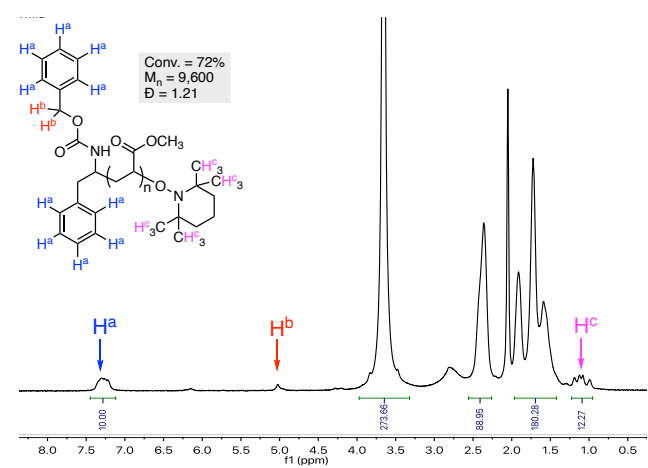

Figure $1-{ }^{1} \mathrm{H}$ NMR spectra of polymer 4 .

${ }^{1} \mathrm{H}$ NMR analysis of polymer 4 (Table 1 , entry 9) clearly showed the presence of aromatic, benzylic and TEMPO derived protons, even after purification by preparative GPC and dialysis, consistent with incorporation of the desired endgroups (Figure 1). Integration of the NMR indicates a 1:1 ration of the $\alpha$ - and $\omega$-endgroups. Further evidence was provided by DOSY NMR analysis, which 
showed the diffusion coefficients associated with the aromatic NMR signal and the signals associated with the bulk polymer of $2.00 \times 10^{-10}$ and $2.07 \times 10^{-10} \mathrm{~m}^{2} \mathrm{~s}^{-1}$, respectively.
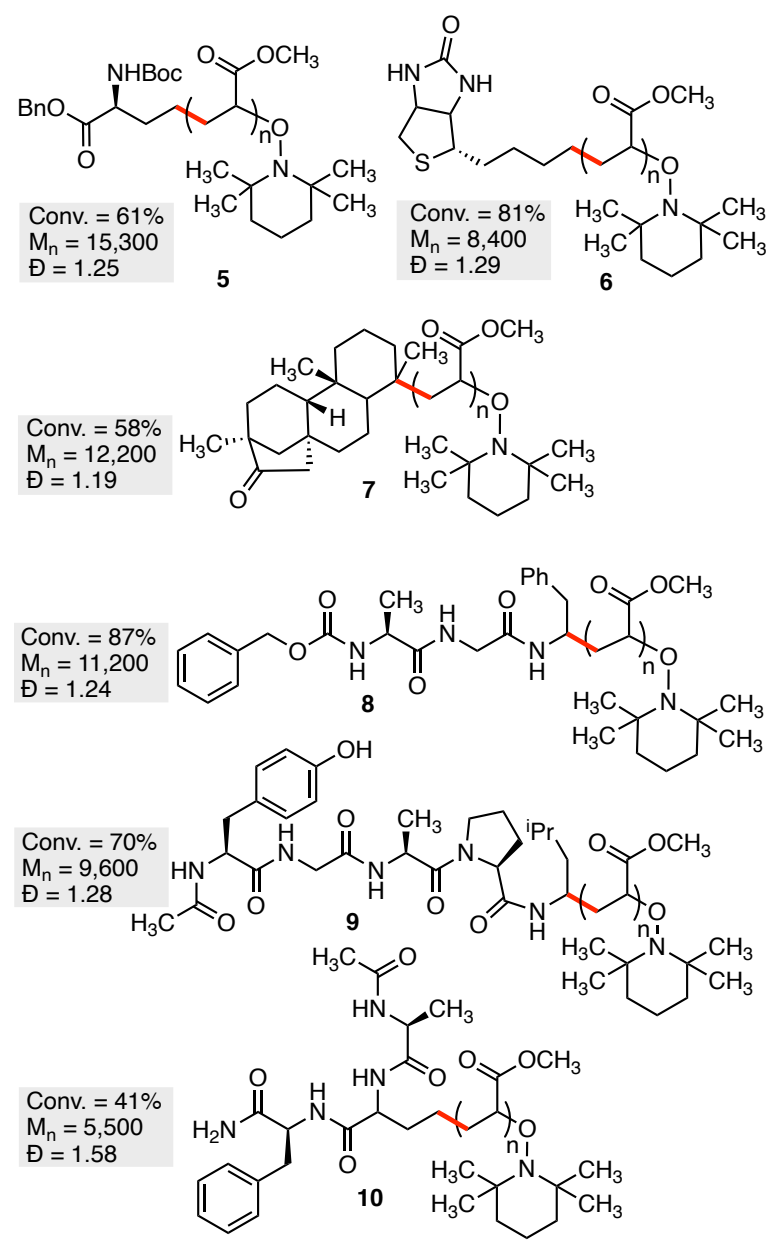

Figure 2 - Functionalised polymers synthesised from redox active esters.

In a control experiment, the diffusion constant for the unreacted ester 3 was found to be $9.09 \times 10^{-10} \mathrm{~m}^{2} \mathrm{~s}^{-1}$ (See SI), indicating that the endgroup NMR signals in polymer 4 are not associated with small molecule impurities. Polymer $\mathbf{4}$ was also analysed by ESIMS after quenching at low conversion (13\%), showing a single major species with intact $\alpha$ - and $\omega$-endgroups (1810.84 calcd. for $\mathrm{n}=16$, found $\left.1810.82,[\mathrm{M}+\mathrm{Na}]^{+}\right)$.

We next examined the ability of our method to initiate polymerisations from primary, secondary and tertiary radicals derived from functionalised carboxylic acid derivatives (Figure 2). This included the incorporation of side-chain activated glutamic acid derivative (5), a biotin group (6) and a complex polycyclic moiety derived from steviol (7). In all cases, the resulting polymerisations proceeded with excellent monomer conversion and low dispersity. In addition, several peptides were successfully incorporated, using a one-pot procedure where the carboxylate was activated in situ using the coupling agent CITU. ${ }^{24}$ Polymers 8 and 9 were synthesised by activation and decarboxylation of the C-terminus, while polymer $\mathbf{1 0}$ was synthesised by decarboxylation of a glutamate residue.

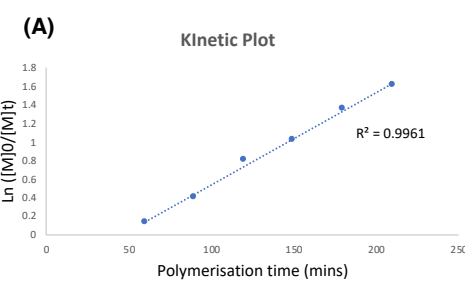

(B)
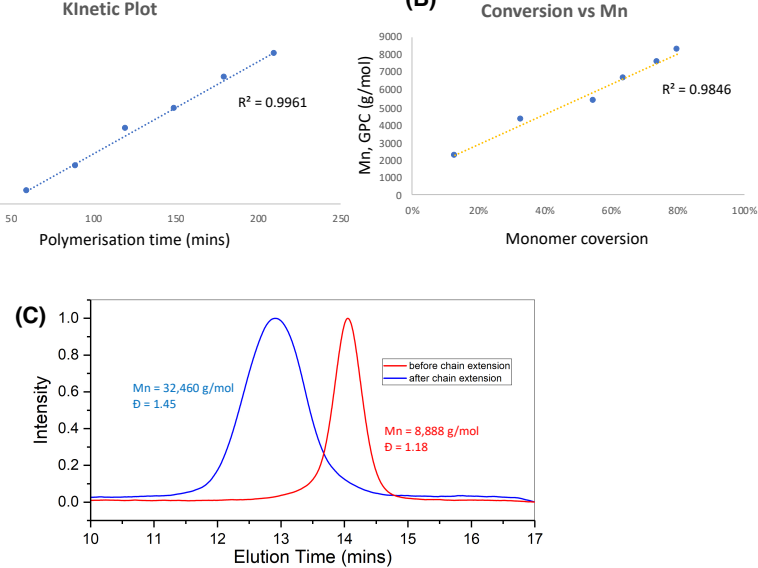

Scheme 2 - (A) Plot of $\operatorname{Ln}\left([\mathrm{M}]_{0} /[\mathrm{M}]_{t}\right)$ vs time, (B) Plot of Mn vs monomer conversion, (C) GPC analysis of polymer before and after chain extension.

Kinetic analysis of the polymerisation to form 4 at $0{ }^{\circ} \mathrm{C}$ showed a linear dependence of $\operatorname{Ln}([\mathrm{M}] \mathrm{o} /[\mathrm{M}])$ versus time following an induction period of approximately 50 minutes (Scheme 2A). A linear increase in molecular weight is observed with increasing conversion (Scheme 2B). These data indicate that irreversible chain termination is not significant under these conditions and that this method shows the characteristics of a living polymerisation. This was also demonstrated through chain extension experiments, where polymerisation under our standard conditions gave $88 \%$ monomer conversion. This was followed by the addition of 100 equivalents of MA before stirring at $6^{\circ} \mathrm{C}$ for $16 \mathrm{~h}$ (Scheme $2 \mathrm{C}$ ). GPC analysis of the polymers before and after chain extension showed a clear shift towards higher molecular weight material, indicating that the organo-cobalt complex at the $\omega$-end of the polymer is still active after the initial polymerisation period. There was, however, a limit to this stability, as chain extension after an initial period of $16 \mathrm{~h}$ at $6^{\circ} \mathrm{C}$ gave a bimodal distribution of polymers with $M_{n}$ of 9,000 and 173,000 . This indicates that chain termination events can be significant when the polymerisation is left at higher temperatures for prolonged periods of time.
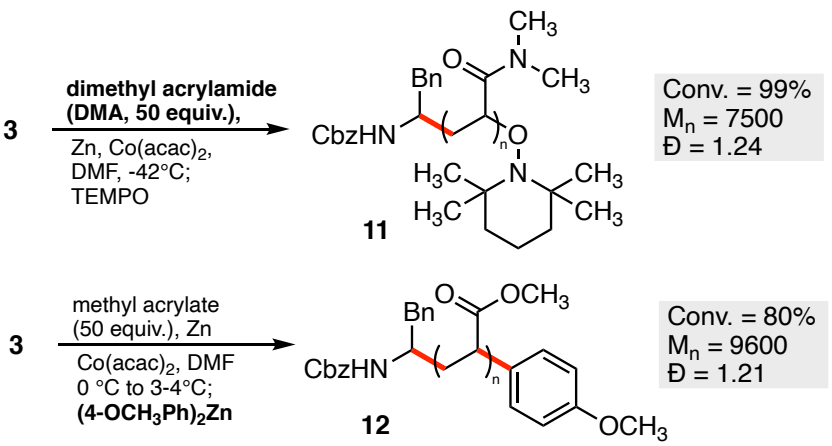

Scheme 3 - Synthesis of polydimethylacrylamide and polymer termination with organozinc. 


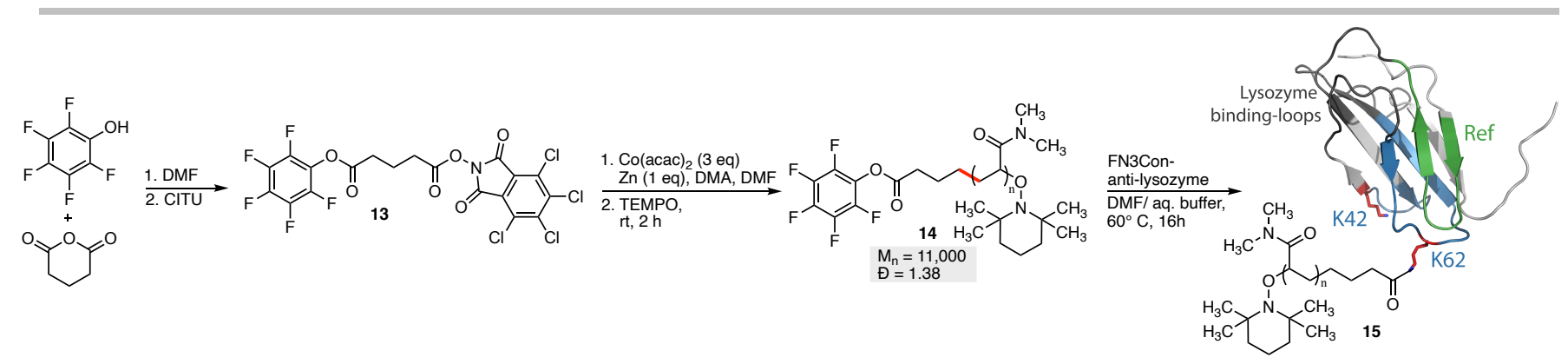

Scheme 4 - Synthesis of the protein conjugate 15

(A) FN3Con-antilysozyme amino-acid sequence and LC/MC peptide fragments

$$
\text { Reference peptide (Ref) }
$$

First lysine (K42)

MASPSPPGNL RVTDVTSTSV TLSWRGYPWA TYYGVEYREA GGEWKOVFTM PGDLSHRYTV TGLKPGTEYE FRVYAVNRVG RTFDTPGPSS VSVTTGSHHH Second lysine (K62)

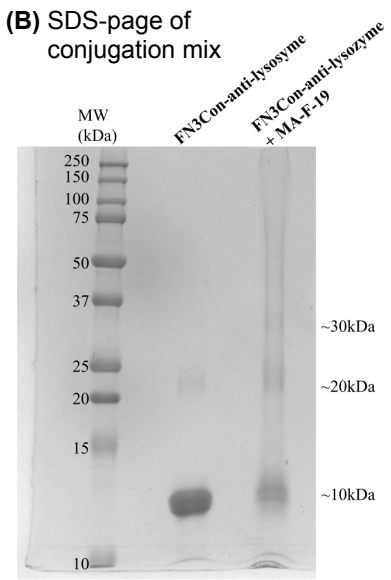

(C) Presence of unconjugated peptide

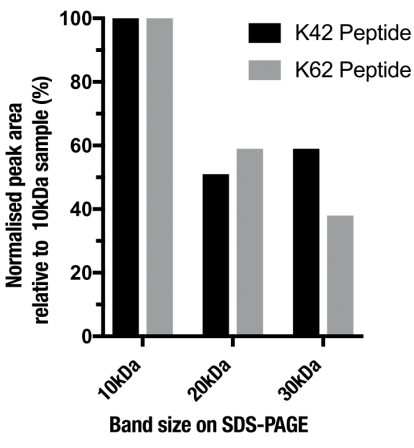

Figure 3 - Conjugation experiments. (A) Amino-acid sequence of FN3Con-antiLys, the reference peptide for normalisation of LC/MS peak area and the peptides that contain lysines for conjugation. (B) SDS-Page, post-overnight incubation at $40^{\circ} \mathrm{C}$. (C) LC/MS measured a $>50 \%$ decrease in presence of either unconjugated peptide in the $20 \mathrm{kDa}$ and $30 \mathrm{kDa}$ species

CMRP has been demonstrated as an effective method for the polymerisation of dimethylacrylamide (DMA), although Coporphyrin, -salen or amino-bis(phenolate) complexes are typically required for controlled polymerisation. ${ }^{28}$ Given our ability to initiate CMRP at low temperatures, we examined the polymerisation of DMA using $\mathrm{Co}(\mathrm{acac})_{2}$, in the hope that lower reaction temperatures would allow for controlled polymerisation. This reaction proceeded rapidly under our optimised conditions at $0{ }^{\circ} \mathrm{C}$, although poor dispersity was observed $(\boxminus=2.70)$. We were pleased to observe that lowering the reaction temperature to $42{ }^{\circ} \mathrm{C}$ resulted in a high level of monomer conversion, while delivering polymer 11 with excellent dispersity $(\boxminus=1.24)$ (Scheme 3).

Based on the cobalt-catalysed cross coupling reaction reported by Wang, ${ }^{23}$ we hypothesized that it should be possible to intercept the organo-cobalt complex at the $\omega$-end of the polymer with an organozinc reagent, resulting in formation of a new C-C bond (Scheme 3). To test this, the activated ester $\mathbf{3}$ was used to initiate polymerization under our standard conditions, however, the reaction was terminated with 2 equivalents of diarylzinc in place of TEMPO. Analysis of the polymer 12 by ${ }^{1} \mathrm{H}$ NMR, DOSY NMR and MALDI-MS indicated clear incorporation of the para-methoxy phenyl group. This demonstrates that cobalt can play three distinct roles in this polymerization reaction, facilitating the incorporation of the $\alpha$-endgroup by radical decarboxylation, mediating the polymerization to control molecular weight and dispersity, and allowing control of the $\omega$-endgroup through transmetalation and reductive elimination from an arylzinc reagent.

As a proof of concept for the application of this methodology we designed poly(dimethylacrylamide) 14, containing a pentafluorophenyl ester at the $\alpha$-end for conjugation to surface lysine residues on a model protein. ${ }^{29}$ Chemical conjugation is critical for increasing the size and PK properties of therapeutic proteins, such as small mini-antibody scaffolds. ${ }^{30,31}$ Monobodies are $10 \mathrm{kDa}$ binding proteins which have previously reached clinical trials using PEGylation for PK enhancement. ${ }^{32}$ This type of chemical conjugation usually requires addition of a cysteine or glutamine residue ${ }^{33}$ however these mutations risk perturbing the structure and sacrificing stability when misplaced in small protein scaffolds like monobodies. ${ }^{34}$ Some recent PK enhancements have come from genetic fusions of albumin-binding domains or extensions of the C-terminus with PAS amino-acid repeats, ${ }^{31,35}$ although this may introduce greater opportunity for protein instability, aggregation or immunogenicity. We chose to conjugate an $11 \mathrm{kDa}$ poly(dimethylacrylamide) to lysines onto the hyperstable FN3Con monobody scaffold, as the robust nature of this scaffold would be amenable to early conjugation experiments. ${ }^{36}$

The FN3Con-anti-lysozyme ${ }^{37}$ is an $11.3 \mathrm{kDa}$ protein that binds the model protein lysozyme with nanomolar affinity and maintains stability up to $87^{\circ} \mathrm{C}$. Critically, in the folded protein structure the lysine conjugation sites are surface exposed and located on the opposite end of the molecule to the binding loops (Scheme 5).

Conjugation of this protein with 50 equivalents of polymer 14 for $16 \mathrm{~h}$ at $40{ }^{\circ} \mathrm{C}$ resulted in higher molecular weight products appearing as bands on SDS-PAGE (Figure 3B), with some SDSresistant dimers of FN3Con occurring in the control sample due to the prolonged exposure to heat stress. For further analysis, we adapted a previously established workflow for monobody conjugation analysis, ${ }^{38}$ where the protein samples undergo trypsin digestion into peptide fragments and LC/MS is used to measure the proportionate loss of unconjugated peptides which contain the target amino-acid. We observe that the $\sim 20 \mathrm{kDa}$ gel band of the conjugation mixture consists of mostly monomeric 11.2kDa FN3Con-anti-lysozyme with $11 \mathrm{kDa} 14$ attached to one of the two lysines (Figure $3 \mathrm{C}$ ). This is due to a $~ 50 \%$ decrease in the presence of either unconjugated peptide fragments (Figure $3 \mathrm{C}$ ) and also suggests that there is no preference for conjugation to one residue over the other. We also used LC/MS to investigate a very faint protein band that appeared at $\sim 30 \mathrm{kDa}$, which may include protein with two polymers attached (Figure 3B). Although there is a small proportion of monomer species where polymer has attached to both conjugation sites, given the $>50 \%$ decrease in the K62 unconjugated peptide (Figure $3 \mathrm{C}$ ), the results show 
that this band is likely to be a complex sample including some quantity of dimerised FN3Con with a single conjugate attached. The successful conjugation of FN3Con-anti-lysozyme with polymer $\mathbf{1 4}$ will allow for the further study of this conjugate, with the hope that increased size will improve the PK properties and increase the circulating half-life in vivo. This study specifically aimed at introducing a non-functional polymer to increase protein size, however this chemistry can be further explored for the conjugation of functional chemical groups onto proteins of therapeutic relevance. Conjugation of a wider range of chemical groups is an avenue for improving the differentiation of the monobody scaffold. ${ }^{39}$ Additionally, the designed robustness of the FN3Con scaffold could enable earlier application of novel functional groups than with scaffolds of lower thermal stability. ${ }^{40}$ In conclusion, we have demonstrated that the radical decarboxylation of tetrachlorophthalimide activated esters by an in situ generated $\mathrm{Co}^{\prime}$ species can initiate CMRP. Incorporation of functional groups derived from activated esters and organozinc reagents into the $\alpha$ - and $\omega$-endgroups of the polymer have been demonstrated by ${ }^{1} \mathrm{H}$ and DOSY NMR spectroscopy and mass spectrometry.

A broad range of functional groups can be included, and primary, secondary and tertiary initiating radicals are all well tolerated. Further, we have produced a proof of concept that CMRP can generate reactive polymers for conjugation to residues on a biological protein scaffold.

\section{References}

1. a)A. Debuigne, R. Poli, C. Jerome, R. Jerome and C. Detrembleur, Prog. Polym. Sci., 2009, 34, 211-239; b)C.-H. Peng, T.-Y. Yang, Y. Zhao and X. Fu, Org. Biomol. Chem., 2014, 12, 8580-8587.

2. J. Demarteau, A. Debuigne and C. Detrembleur, Chem. Rev., 2019, 119, 6906-6955.

3. A. Debuigne, C. Jerome and C. Detrembleur, Polymer, 2017, 115, 285-307.

4. a)A. Debuigne, J.-R. Caille and R. Jerome, Angew. Chem. Int. Ed., 2005, 44, 1101-1104; b)T. T. Silva, Y. F. Silva, A. E. H. Machado, P. I. S. Maia, C. R. B. Tasso, B. S. Lima-Neto, J. L. Silva Sa, V. P. Carvalho-Jr, N. C. Batista and B. E. Goi, J. Macromol. Sci., Part A: Pure Appl. Chem., 2019, 56, 1132-1140.

5. A. Debuigne, M. Schoumacher, N. Willet, R. Riva, X. Zhu, S. Ruetten, C. Jerome and C. Detrembleur, Chem. Commun. 2011, 47, 12703-12705.

6. T. Zeng, W. You, G. Chen, X. Nie, Z. Zhang, L. Xia, C. Hong, C. Chen and Y. You, iScience, 2020, 23, 100904.

7. a)R. Bryaskova, N. Willet, P. Degee, P. Dubois, R. Jerome and C. Detrembleur, Journal of Polymer Science, Part A: Polym. Chem., 2007, 45, 2532-2542; b)A. Kermagoret, A. Debuigne, C. Jerome and C. Detrembleur, Nat. Chem., 2014, 6, 179-187.

8. J. Demarteau, B. Ameduri, V. Ladmiral, M. A. Mees, R. Hoogenboom, A. Debuigne and C. Detrembleur, Macromolecules, 2017, 50, 3750-3760.

9. L. D. Arvanitopoulos, M. P. Greuel, B. M. King, A. K. Shim and H. J. Harwood, ACS Symp. Ser. Am. Chem. Soc., 1998, 685, 316-331.

10. a)J. Demarteau, A. Kermagoret, I. German, D. Cordella, K. Robeyns, J. De Winter, P. Gerbaux, C. Jerome, A. Debuigne and C. Detrembleur, Chem. Commun., 2015, 51, 14334-14337; b)J. Demarteau, J. De Winter, C. Detrembleur and A. Debuigne, Polym. Chem., 2018, 9, 273-278.

11. A. Debuigne, J.-R. Caille and R. Jerome, Macromolecules, 2005, 38, 5452-5458

12. C. Detrembleur, O. Stoilova, R. Bryaskova, A. Debuigne, A. Mouithys-Mickalad and R. Jerome, Macromol. Rapid Commun., 2006, 27, 498-504.
13. J.-M. Thomassin, I. Molenberg, I. Huynen, A. Debuigne, M Alexandre, C. Jerome and C. Detrembleur, Chem. Commun., 2010, 46, 3330-3332.

14. A. Debuigne, R. Poli, J. De Winter, P. Laurent, P. Gerbaux, P. Dubois, J.-P. Wathelet, C. Jerome and C. Detrembleur, Chem. Eur. J. 2010, 16, 1799-1811.

15. aE. M. Pelegri-O'Day, E.-W. Lin and H. D. Maynard,J. Am. Chem. Soc., 2014, 136, 14323-14332; bF. Moncalvo, E. M. I. Martinez and F. Cellesi, Front. Bioeng. Biotechnol., 2020, 8, 89.

16. J. H. Ko and H. D. Maynard, Chem. Soc. Rev., 2018, 47, 89989014.

17. Y. Jin and H. Fu, Asian J. Org. Chem., 2017, 6, 368-385.

18. K. Okada, K. Okamoto, N. Morita, K. Okubo and M. Oda, J. Am. Chem. Soc., 1991, 113, 9401-9402.

19. J. Cornella, J. T. Edwards, T. Qin, S. Kawamura, J. Wang, C.-M Pan, R. Gianatassio, M. Schmidt, M. D. Eastgate and P. S. Baran, J. Am. Chem. Soc., 2016, 138, 2174-2177.

20. K. M. M. Huihui, J. A. Caputo, Z. Melchor, A. M. Olivares, A. M. Spiewak, K. A. Johnson, T. A. DiBenedetto, S. Kim, L. K. G. Ackerman and D. J. Weix, J. Am. Chem. Soc., 2016, 138, 50165019.

21. J. Wang, T. Qin, T.-G. Chen, L. Wimmer, J. T. Edwards, J. Cornella, B. Vokits, S. A. Shaw and P. S. Baran, Angew. Chem. Int. Ed., 2016, 55, 9676-9679.

22. a)L. Huang, A. M. Olivares and D. J. Weix, Angew. Chem. Int. Ed., 2017, 56, 11901-11905; b)J. M. Smith, T. Qin, R. R. Merchant, J. T. Edwards, L. R. Malins, Z. Liu, G. Che, Z. Shen, S. A. Shaw, M. D. Eastgate and P. S. Baran, Angew. Chem. Int. Ed., 2017, 56, 11906-11910.

23. X.-G. Liu, C.-J. Zhou, E. Lin, X.-L. Han, S.-S. Zhang, Q. Li and H. Wang, Angew. Chem. Int. Ed., 2018, 57, 13096-13100.

24. J. N. deGruyter, L. R. Malins, L. Wimmer, K. J. Clay, J. LopezOgalla, T. Qin, J. Cornella, Z. Liu, G. Che, D. Bao, J. M. Stevens, J. X. Qiao, M. P. Allen, M. A. Poss and P. S. Baran, Org. Lett, 2017, 19, 6196-6199.

25. R. Bryaskova, C. Detrembleur, A. Debuigne and R. Jerome, Macromolecules, 2006, 39, 8263-8268.

26. J. Lal, Journal of Polymer Science, Part A-1: Polym. Chem., 1966, 4, 1163-1177.

27. A. M. Schaiberger and J. A. Moss, J. Am. Soc. Mass Spectrom., 2008, 19, 614-619.

28. a)Y. Zhao, H. Dong, Y. Li and X. Fu, Chem. Commun., 2012, 48 3506-3508; b)X. Chen, L. Wang, Q. Li, J. Zhang, J. Wang, J. Sun and Y. Zhang, J. Macromol. Sci., Part A: Pure Appl. Chem., 2020, 57, 743-750.

29. G. H. Pham, W. Ou, B. Bursulaya, M. Di Donato, A. Herath, Y. Jin, X. Hao, J. Loren, G. Spraggon, A. Brock, T. Uno, B. H. Geierstanger and S. E. Cellitti, ChemBioChem, 2018, 19, 799804.

30. R. Vazquez-Lombardi, T. G. Phan, C. Zimmermann, D. Lowe, L. Jermutus and D. Christ, Drug Discov. Today, 2015, 20, 12711283.

31. Z. R. Crook, N. W. Nairn and J. M. Olson, Trends Biochem. Sci., 2020, 45, 332-346.

32. a)R. Mamluk, I. M. Carvajal, B. A. Morse, H. Wong, J. Abramowitz, S. Aslanian, A.-C. Lim, J. Gokemeijer, M. J. Storek, J. Lee, M. Gosselin, M. C. Wright, R. T. Camphausen, J. Wang, Y. Chen, K. Miller, K. Sanders, S. Short, J. Sperinde, G. Prasad, S. Williams, R. Kerbel, J. Ebos, A. Mutsaers, J. D. Mendlein, A. S. Harris and E. S. Furfine, MAbs, 2010, 2, 199-208; b)D. Schiff, S. Kesari, J. de Groot, T. Mikkelsen, J. Drappatz, T. Coyle, L. Fichtel, B. Silver, I. Walters and D. Reardon, Invest. New Drugs, 2015, 33, 247-253.

33. Q. Zhou, Biomedicines, 2017, 5.

34. S. D. Goldberg, R. M. F. Cardoso, T. Lin, T. Spinka-Doms, D. Klein, S. A. Jacobs, V. Dudkin, G. Gilliland and K. T. O'Neil, Protein Eng., Des. Sel., 2016, 29, 563-572.

35. a)S. A. Jacobs, A. C. Gibbs, M. Conk, F. Yi, D. Maguire, C. Kane and K. T. O'Neil, Protein Eng., Des. Sel., 2015, 28, 385-393; b)S. Aghaabdollahian, R. Ahangari Cohan, D. Norouzian, F. Davami, M. R. Asadi Karam, F. Torkashvand, G. Vaseghi, R. Moazzami and S. Latif Dizaji, Sci. Rep., 2019, 9, 1-14.

36. B. T. Porebski, A. A. Nickson, D. E. Hoke, M. R. Hunter, L. Zhu, S. McGowan, G. I. Webb and A. M. Buckle, Protein Eng., Des. Sel., 2015, 28, 67-78.

37. B. T. Porebski, P. J. Conroy, N. Drinkwater, P. Schofield, R. Vazquez-Lombardi, M. R. Hunter, D. E. Hoke, D. Christ, S. 
McGowan and A. M. Buckle, Protein Eng., Des. Sel., 2016, 29, 541-550.

38. C. Shi, S. Goldberg, T. Lin, V. Dudkin, W. Widdison, L. Harris, S. Wilhelm, Y. Jmeian, D. Davis, K. O'Neil, N. Weng and W. Jian, Bioanalysis, 2018, 10, 1651-1665.
39. P. G. Chandler and A. M. Buckle, Cells, 2020, 9, 610.

40. P. G. Chandler, S. S. Broendum, B. T. Riley, M. A. Spence, C. J. Jackson, S. McGowan and A. M. Buckle, Methods Mol. Biol. 2020, 2073, 163-181. 